Original Research Article

\title{
Drug utilization for common skin diseases: an outpatient based study
}

\author{
Vijay Haribhau Mate ${ }^{1 *}$, Satish Balaji Gonarkar ${ }^{2}$, Anjum Mehmood Dhamani ${ }^{1}$
}

\begin{abstract}
${ }^{1}$ Department of Pharmacology, Bharati Vidyapeeth (Deemed to be University) Medical College, Pune, Maharashtra, India ${ }^{2}$ Drug Safety Physician (Crest Media Solutions)
\end{abstract}

Received: 29 September 2019 Revised: 15 November 2019 Accepted: 18 November 2019

\section{*Correspondence to:}

Dr. Vijay Haribhau Mate, Email: vijayhmate@gmail.com

Copyright: (C) the author(s), publisher and licensee Medip Academy. This is an openaccess article distributed under the terms of the Creative Commons Attribution NonCommercial License, which permits unrestricted noncommercial use, distribution, and reproduction in any medium, provided the original work is properly cited.

\begin{abstract}
Background: Drug utilization studies are useful for understanding the pattern of drug use in any particular healthcare set-up. This data gives an insight to improve the medical treatment at different layers in the health system. The oobjective of the present study was to assess drug utilization patterns by using core prescribing indicators of WHO and to assess most commonly observed skin disease in Dermatology out patients department (OPD) of tertiary care hospital.
\end{abstract}

Methods: 246 prescriptions from Dermatology OPD were audited. Common skin diseases and the prescribing patterns were analysed from the prescriptions. Results: Average 2.4 drugs per prescription were seen in this study. $38.7 \%$ drugs were from National Essential Drug List of India. All the drugs were prescribed by brand names. The fixed dose combinations accounted for $20.6 \%$ drugs prescribed. Dosage, dose and duration of treatment were written for $100 \%$ of prescriptions. Around 44 different skin diseases were diagnosed amongst 246 patients predominantly cutaneous fungal infections, acne, dermatitis, eczema and psoriasis. About 591 different drugs were used mainly corticosteroids $(21 \%)$, antibiotics $(17 \%)$, anti-allergic $(16 \%)$, antifungals $(11 \%)$. Common skin conditions receiving corticosteroids were dermatitis $(9.9 \%)$, eczema $(9.1 \%)$. Antibiotics (17\%), antifungals (11\%) and antivirals (1\%) were commonly used antimicrobial agents. $55.2 \%$ drugs were administered topically while $44.6 \%$ received orally.

Conclusions: Prescriptions revealed a higher incidence of fungal and bacterial infections. All the medications were prescribed rationally. All prescriptions had proper dosage form, frequency of administration, duration of therapy and diagnosis. However, prescriber should be motivated for prescription of generic drugs and those from essential drug list.

Keywords: Dermatology, Treatment, Core prescribing indicators

\section{INTRODUCTION}

Skin diseases affect all ages from neonate to the elderly. It causes harm in number of ways and can have a profound effect on both the individual and the community. Morbidity is significant through disfigurement, disability or symptoms such as intractable itch, as is the reduction in quality of life, even social isolation and economic burden. Death, though rare but still seen from metastatic skin cancer. ${ }^{1}$

There is a difference between the patterns of skin diseases from country to country and even amongst various regions of a single country. ${ }^{2}$ Types of skin diseases are influenced by various factors like genetic, race, religion, occupation, nutrition, habits etc. Geographical factors such as season and climate also contribute to the increased prevalence of certain type of skin disorder in a particular area. ${ }^{1}$ Climate, socioeconomic status, religions and customs varies in different parts of India. ${ }^{3}$ In developing countries, other than hot and humid climatic condition, low hygiene, poor access to water, overcrowding, high interpersonal contact also play significant etiological role for certain skin diseases like pyoderma, scabies,fungal infection. ${ }^{4}$ 
Irrational prescribing of drugs is common in clinical practice. ${ }^{5}$ Such irrational drug use not only increases the cost of therapy in developing countries but may sometimes have real risks but no objective benefits to the patients. ${ }^{6}$ Therefore, periodic auditing of prescriptions is essential to improve the benefit to risk ratio and at the same time to provide feedback to the prescribers. ${ }^{7}$

Such studies enhances the excellence of medical treatment at all stratas in the health system. Polypharmacy is defined by the World Health Organisation as "the administration of many drugs at the same time or the administration of an excessive number of drugs". Challenges like poly-pharmacy, drug-drug interaction and adverse drug reaction can be distinguished by such analysis. ${ }^{8-10}$ The present study was planned to understand the pattern of drug use for common skin conditions and core drug prescribing indicators of World Health Organization (WHO) in the dermatology out-patient department (OPD) at tertiary care hospital in Pune, India.

\section{METHODS}

The study was observational study, conducted from March 2015 to April 2015. All patients of either gender getting treated on OPD basis and willing to participate in the study were enrolled. Study was started after obtaining institutional ethics committee approval (No. BVDU/MC/E5) and written informed consent of physicians from Dermatology department for viewing their patient's prescriptions.

Data collected included the demographic profile (age, gender and locality), various drugs prescribed with their dosage form, dose, route, frequency and duration of administration, average number of drugs prescribed, drugs prescribed by generic or brand name, drug from essential drug list (EDL) and fixed dose combinations (FDCs). All the details were noted down on "detailed indicator encounter form" and "prescribing indicator form " developed by WHO. Cutaneous adverse drug reactions were not included in this study. The cost of various preparations of drugs was obtained from current index of medical specialties (CIMS) and cost analysis per prescription was evaluated. Data was coded as per the WHO Anatomical and Chemical Classification coding system (ATC) and entered on excel sheet for analysis. ${ }^{11}$ For generics and EDL, WHO $4^{\text {th }}$ edition, April 2013 for children and $19^{\text {th }}$ edition, April 2015 and Indian EDL 2015 was considered as a standard. ${ }^{12,13}$ Data was also analyzed to find out commonly used drugs using WHO ATC Classification coding system and common conditions for which patients came to Dermatology OPD according to WHO ICD classification version $2010 .{ }^{14}$

\section{Statistical analysis}

Results are entered in Microsoft Excel and expressed in percentage or frequencies.

\section{RESULTS}

Total 246 prescriptions from the dermatology OPD were analyzed during the study period. Table 1 depicts the demographic details of the participants where majority of them were from age group 21-30 years, followed by age group 11-20 years [Table 1].

Table 1: Demographic details of study participants.

\begin{tabular}{|ll|}
\hline Parameter & $\mathbf{N}(\%)$ \\
\hline Gender & \\
\hline Male & $124(50.4)$ \\
\hline Female & $122(49.6)$ \\
\hline Age & \\
\hline Less than 10 & $22(8.9)$ \\
\hline $11-20$ & $47(19.1)$ \\
\hline $21-30$ & $81(32.9)$ \\
\hline $31-40$ & $39(15.8)$ \\
\hline $41-50$ & $18(7.3)$ \\
\hline $51-60$ & $25(10.2)$ \\
\hline Above 60 & $14(6.7)$ \\
\hline Locality & \\
\hline Urban & $202(82.1)$ \\
\hline Rural & $44(17.9)$ \\
\hline
\end{tabular}

Table 2: WHO "core drug prescribing indicators" in the study prescriptions.

\begin{tabular}{|ll|}
\hline Observations & Frequency \\
\hline Number of prescriptions & 246 \\
\hline Number of drugs prescribed & 590 \\
\hline $\begin{array}{l}\text { Average number of drugs per } \\
\text { prescription }\end{array}$ & 2.4 \\
\hline Drugs from EDL & $38.7 \%$ \\
\hline Drugs prescribed by generic name & $0 \%$ \\
\hline Encounters with antibiotics & 80 \\
\hline Encounters with an injection & 1 \\
\hline FDC & $20.6 \%$ \\
\hline
\end{tabular}

The WHO core drug prescribing indicators (Table 2) show that average 2.4 drugs were prescribed per prescription and $38.7 \%$ drugs were from National Essential Drug List of India. All the drugs were prescribed by brand names. The FDCs accounted for $20.6 \%$ drugs prescribed. Dosage, dose and duration of treatment was written for $100 \%$ of prescriptions. There was no use of any banned drug (Table 2).

Around 44 different skin diseases were diagnosed amongst 246 patients. It reveals predominant skin diseases like cutaneous fungal infections (13\%), acne $(11 \%)$, dermatitis $(11 \%)$, eczema $(8 \%)$, psoriasis $(8 \%)$, vitiligo (5\%) and scabies (3\%). Other skin diseases found in our study were folliculitis, alopecia, urticaria, furuncle, herpes simplex viral infection, hypersensitivity reactions, hypopigmentation etc. 


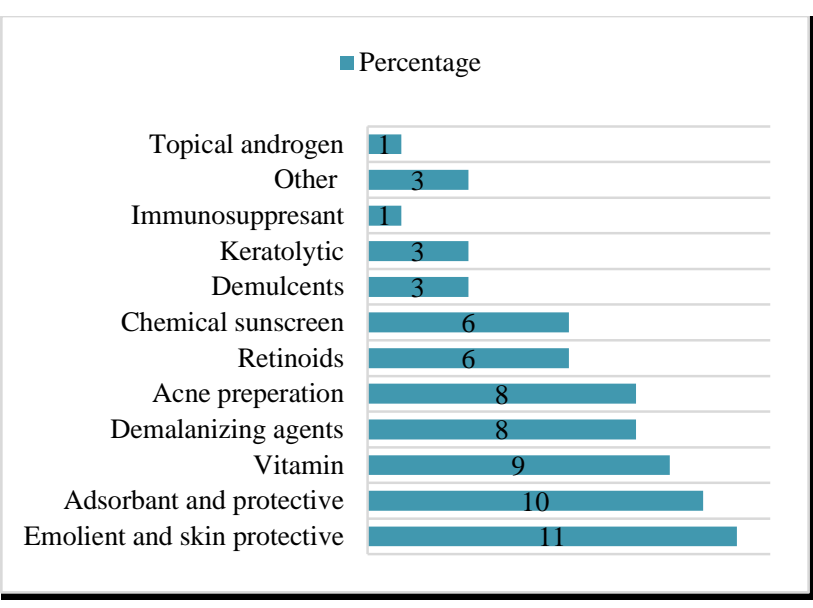

Figure 1: Miscellaneous classes of drugs prescribed among study participants.

About 591 different classes of drugs were used in all 246 patients like corticosteroids (20.5\%), antibiotics (17.1\%), anti-allergics (16.2\%), antifungals (11\%) and others (26.7\%). Emollient, adsorbents, vitamins, demelanizing agents, acne preparations, retinoid, chemical sunscreen, demulcents and keratolytics are miscellaneous classes of drugs as seen Figure 1.

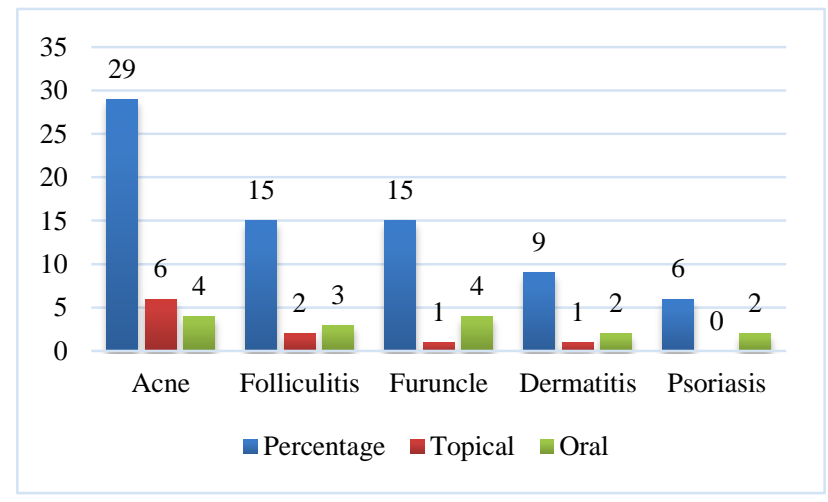

\section{Figure 2: Skin diseases treated with antibiotics among the study participants.}

Common skin conditions receiving corticosteroids were dermatitis $(9.9 \%)$, eczema $(9.1 \%)$, psoriasis $(5.8 \%)$, vitiligo $(5.8 \%)$, followed by lichen planus, urticaria, alopecia and hypersensitivity reaction. Major route of administration of corticosteroids was topical $(67.8 \%)$ followed by oral $(30.2 \%)$. Only 1 patient (alopecia areata) received corticosteroid by parenteral route.

Antibiotics (17\%), antifungals (11\%) and antivirals (1\%) were commonly used antimicrobial agents (AMA). Most of these AMAs (52\%) were administered topically and were prescribed for acne, folliculitis, furuncle, dermatitis and psoriasis. No AMA was prescribed by injectable route [Figure 2].

Out of 97 anti-allergic drugs prescribed, levocetrizine was the most commonly used drug $(68 \%)$ followed by hydroxyzine $(22.7 \%)$. Desloratidine $(4.1 \%)$ and fexofenadine $(2.1 \%)$ were used less frequently. All antiallergic drugs were given orally.

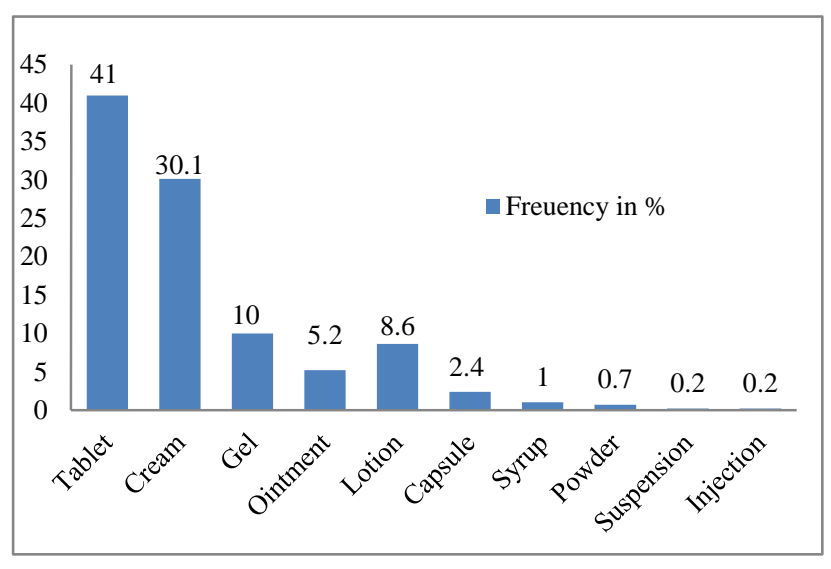

Figure 3: Different formulations used in dermatology OPD during the study.

65 prescriptions had anti-fungal drugs, $46.2 \%$ of those were given orally and $53.8 \%$ topically. Amongst the oral anti-fungal agents, Terbinafine was used in $53.4 \%$ cases followed by fluconazole (40\%). Ketoconazole (34.3\%) and miconazole $(28.6 \%)$ were commonly prescribed topical antifungal agents.

Amongst all medications, 55.2\% drugs were administered topically while $44.6 \%$ were given orally. Only one patient received drug parenterally. Amongst topically applied drugs, $78 \%$ were used in combinations while $22 \%$ were used as single drugs. Corticosteroids, antibiotics, antifungals, emollients, adsorbents, anti-acne medications and demyelinising drugs were predominantly given by topical route. Common indications for topical treatment were acne, dermatitis, and eczema.

Amongst orally administered drugs, $60 \%$ drugs were used in combinations while $40 \%$ were used as single drugs. Antihistaminics, antifungals and antibiotics were given by oral route. Cutaneous fungal infections, acne, dermatitis were the predominant indications for oral medications.

As seen in Figure 3, $41 \%$ drug formulations were in tablet forms followed by topical preparations like cream $(30.1 \%)$, gel $(10 \%)$, lotion $(8.6 \%)$, and ointment $(5.2 \%)$ [Figure 3]. The cost of various preparations of drugs was obtained from CIMS and cost analysis per prescription was evaluated. In our study, it was found to be 233.2 INR per prescription. Total 167 antibiotics were prescribed out of which 81 drugs $(48.5 \%)$ were prescribed by oral route and 86 drugs $(51.5 \%)$ by topical route.

\section{DISCUSSION}

Skin disorders constitute $10-30 \%$ of outpatient attendance in any hospital and are often easily noticed by others, 
hence a cause of great social concern to the patient. The prescription by a doctor demonstrates physician's attitude towards the disease and the role of drugs in its treatment. A clear message to the prescribing physician is provided by dermatological prescription analysis to achieve rational medical care. ${ }^{15}$

There are few drug utilization studies already carried out in developed and developing countries like India., ${ }^{2,3}$ Patterns of drug consumption does exhibit quantitative and qualitative geographical differences and hence the variation in results of studies conducted in developed and developing countries. ${ }^{16}$ Studies are done in India at both hospital and community levels. However, the information from these studies is not adequate to get an idea of drug use at this healthcare levels. ${ }^{17}$

Study site, teaching hospital, being located in suburban part of the city, $82 \%$ of patients were from urban area and only $18 \%$ from rural area. In this study, various core drug prescribing indicators of WHO) were assessed. The important indicator of prescription analysis is average number of drugs used which was 2.4 in this study. The findings of this study were similar to those conducted in other Indian hospitals and found 2-3 drugs per prescription. Increased risk of drug-drug interactions, adverse drug reactions, poor medication adherence and increased cost of therapy is mostly associated with higher number of drugs per prescription. This is the reason to keep the average number of drugs per prescription as low as possible. ${ }^{16}$ To keep less number of drugs in the prescription is also the professional skill of clinician. The dose, duration and frequency of the drugs were mentioned in all the prescription correctly which showed rational and appropriate use of drugs. Irrational prescriptions usually indicate lack of training on the part of the prescriber.

Our analysis revealed $38.7 \%$ of drugs from EDL, while Biswas et al and Georgekutty et al reported $95.78 \%$ and $51 \%$ respectively. ${ }^{18,19}$ The study center being private tertiary care hospital where advanced treatment was available, the newer drugs had been used which were not yet included in the EDL. Study center being a private medical college hospital, there was no compulsion to prescribe from the EDL but drugs from EDL were seen to be prescribed. ${ }^{16}$ It is economical and rational to prescribe under a generic name but our study revealed all the patients were prescribed brand drugs which was consistent with studies done by Biswas et al. ${ }^{18} 6.32 \%$ generic drug prescribed as against $93.68 \%$ branded drugs and Shankar et al $32.6 \%$ generic drugs prescribed, remaining being branded drugs). ${ }^{20}$ Poor prescribing of generic drugs can be because of many reasons, one of which is the concern about their quality.

Cutaneous fungal infections and acne vulgaris were the commonly encountered skin diseases. The distribution of cutaneous fungal infections and their causative agents vividly differ between geographical, climatic factor, and cultural requirements, and also show differences due to changes in lifestyle, habit, sanitary thought, and socioeconomic status, as well as frequent interchange, trade, and human immigration. Acne vulgaris is a disease of younger age group which was evident from the present study. The study was done in summer-monsoon season therefore prescriptions revealed a higher incidence of fungal and bacterial infections.

Drugs were mostly prescribed by topical route in this study, which was similar to that reported by other authors. $^{18,21}$ The use of topical preparations for treating skin diseases is recommended as they have site specific action, less systemic absorption resulting in less side effects and convenience for patient use.

Polypharmacy was observed in $87.4 \%$ of prescriptions. It should be restricted as most of the times it is unnecessary, increases the morbidity by pharmacokinetic and pharmacodynamic drug interactions and ultimately increases the cost of treatment. ${ }^{22}$ The FDCs were prescribed in $20.7 \%$ patients. Kshirsagar et.al. $(1998)^{23}$ revealed lower percentage of FDCs prescribed. However, use of FDCs is many times indicated as it involves multimodality approach, low cost and better compliance.

Study revealed corticosteroids (mainly steroid+antifungal topical preparations) as the most commonly prescribed drug class followed by antibiotics. Our study findings differs from the study carried out by Narwane et al which shows antiallergics and then antifungals are the most commonly prescribed drugs. ${ }^{22}$ Skin diseases encountered during this study were consistent with those mentioned by Vineeta et al i.e., dermatitis, eczema, psoriasis, vitiligo, lichen planus, urticaria, alopecia, hypersensitivity reactions etc. ${ }^{24}$ As these are chronic conditions of the skin and steroids need to be given orally as well as topically to the same patient at a time, number of steroid usage is seen to be increased.

Considering the economic burden and high prevalence of the skin diseases, it was of interest to study the cost or prescription. This study findings showed the average cost of 233.2 INR per prescription which was quite less than Vineeta et al and higher than Narwane et al study which reported the average cost of 376.97 INR and 135.60 INR respectively. ${ }^{22,24}$ The reason behind cost rise/reduction may be due to study site being private/municipal corporation hospital.

\section{CONCLUSION}

The study was done in summer-monsoon season (MarchApril 2015) therefore prescriptions revealed a higher incidence of fungal and bacterial infections. A similar study in winters would exhibit a trend for different dermatological indications. Medications in all the prescriptions were showing proper dosage forms, frequency of administration and duration of therapy. Diagnosis of the patients was also observed in all the 
prescriptions. However, prescriber should be motivated for more use of generic drugs and drugs from EDL. EDL should be updated regularly and made available to all the physicians at all the times.

Funding: No funding sources Conflict of interest: None declared

Ethical approval: The study was approved by the Institutional Ethics Committee

\section{REFERENCES}

1. Baur B, Sarkar J, Manna N, Bandyopadhyay L. The pattern of dermatological disorders among patients attending skin OPD of a tertiary care hospital in Kolkatta, India. J Dent Med Sci. 2013;3(4):04-9.

2. Rook A, Savin JA, Wilkinson DS. The Prevalence, incidence and ecology of diseases of skin. In: Rook A, Wilkinson DS, Ebling FJ, Champion RH, Burton JL, ed. Text book of Dermatology. Mumbai, India: Oxford University Press; 1987: 39-53.

3. Devi TB, Zamzachin G. Pattern of skin diseases in Imphal. Indian J Dermatol. 2006;51(2):149-50.

4. Gupta V. Pattern of skin diseases in rural India: a hospital based study. Intl J Scientific Stud. 2015;3(1):44-7.

5. Soumerai SB. Factors influencing prescribing. Aust J Hosp Pharm. 1988;18:9-16.

6. Lamichhane DC, Giri BR, Pathak OK, Panta OB, Shankar PR. Morbidity profile and prescribing patterns among outpatients in a teaching hospital in Western Nepal. McGill J Med. 2006;9(2):126-33.

7. Krishnaswamy K, Kumar DB, Radhaiah G. A drug use survey- precepts and practice. Eur J Clin Pharmacol. 1985;29:363-70.

8. Michael JC, John T, Catherine H, Julie C, Victoria B, Rachid TA, et al. An audit of adverse drug reactions to aqueous cream in children with atopic eczema. The Pharmaceut J. 2003;271:747-8.

9. Sweileh WM. Audit of prescribing practices of topical corticosteroids in outpatient dermatology clinics in north Palestine. East Mediterran Health J. 2006;12(1/2):161-9.

10. Chester BG. Polypharmacy in elderly patients with diabetes. Diab Spectrum. 2002;15(4):240-8.

11. WHO Anatomical and Chemical Classification coding system (ATC/DDDIndex), 2013. Available at: http://www.whocc.no/atc_ddd_index/. Accessed on 16 January 2019.

12. World Health Organization. Model list of essential drug list for children, 2013. 4th ed; and World Health Organization. Model list of essential drug, 2015. 19th ed. Available at: http://www.who.int/medicines/publi cations/essentialmedicines/en/. Accessed on 16 January 2019.
13. National list of essential medicines of India. 2015. Avilable at: https://mohfw.gov.in > sites > default > files. Last accessed 16 January 2019.

14. World Health Organization: WHO ICD-10: Version 2010. Available at: http://apps.who.int/classifications /icd10/browse/2010/en. Accessed on 16 January 2019.

15. Thappa DM, Microanatomy of the Skin. Thappa DM, ed. In: Essential in Dermatology Microanatomy of the skin. 2nd ed. New Delhi; Jaypee Brothers Medical publishers; 2009: 1- 8 .

16. Tikoo D, Chopra SC, Kaushal S, Dogra A. Evaluation of drug use pattern in dermatology as a tool to promote rational prescribing, JK Science. J Med Educ Res. 2011;13(3):128-31.

17. Minocha KB, Bajaj S, Gupta K, Gupta M. A clinico pharmacological study of outpatient prescribing pattern of dermatological drugs in an Indian tertiary hospital. Indian J Pharmacol. 2000;32:384-5.

18. Biswas NR, Biswas RS, Pal PS, Jain SK, Malhotra SP, Gupta A, et al. Patterns of prescriptions and drug use in two tertiary hospitals in Delhi. Indian J Physiol Pharmacol. 2000;44:109-12.

19. Georgekutty KV, Sambasivam N, Nagarajan M. A study on drug prescribing pattern in Madurai city. Indian J Pharmacol. 2002;34:361-2.

20. Shankar RP, Partha P, Nagesh S. Prescribing patterns in medical outpatients. Int J Clin Pract. 2002;56:54951.

21. Maini R, Verma KK, Biswas NR, Agrawal SS. Drug utilization study in dermatology in a tertiary hospital in Delhi. Indian J Physiol Pharmacol. 2002;46:10710.

22. Narwane SP, Patel TC, Shetty YC, Chikhalkar SB. Drug Utilization and cost analysis for common skin diseases in dermatology OPD of an Indian tertiary care hospital- a prescription survey. Br J Pharm Res. 2011;1(1):9-18.

23. Kshirsagar MJ, Langade D, Patil S, Patki PS. Prescribing patterns among medical practitioners in Pune, India. Bull World Health Organization. 1998;76(3):271-5.

24. Vineeta D, Sharad P, Ganachari MS, Santosh S. Assessment of drug prescribing pattern and cost analysis for skin disease in dermatological department of tertiary care hospital: an interventional study. J Pharmacovigil. 2016;4:3.

Cite this article as: Mate VH, Gonarkar SB, Dhamani AM. Drug utilization for common skin diseases: an outpatient based study. Int J Basic Clin Pharmacol 2019;8:2604-8. 